\title{
EMISIONES GASEOSAS DE UN RELLENO SANITARIO EN MÉXICO. COMPARACIÓN CON LOS MODELOS DE GENERACIÓN DE BIOGÁS
}

\author{
Francisco J. COLOMER MENDOZA ${ }^{1 *}$, Ferran GARCÍA DARÁS ${ }^{1}$, Joan ESTEBAN ALTABELLA ${ }^{1}$, \\ Fabián ROBLES MARTÍNEZ² y Gil ARANDA ${ }^{3}$
}

\footnotetext{
${ }^{1}$ INGRES, Ingeniería de Residuos, Universidad Jaume I. Avda. Vicent Sos Baynat, S/N. 12071 Castellón (España)

${ }^{2}$ Instituto Politécnico Nacional, Unidad Profesional Interdisciplinaría de Biotecnología. Av. Acueducto S/N. Barrio la Laguna-Ticomán, CP 07340, México D.F.

${ }^{3}$ CAPPY \& ASSOCIATES, Mex. SA de CV. Ejercito Nacional no 373-501, Colonia Granada-Polanco. CP 11520 México D.F.

*Autor para correspondencia: fcolomer@uji.es
}

(Recibido noviembre 2014; aceptado junio 2015)

Palabras clave: relleno sanitario, biogás, modelo matemático

\begin{abstract}
RESUMEN
Para poder prever la generación de biogás en un relleno sanitario (vertedero) existen una serie de modelos matemáticos que calculan con mayor o menor exactitud esta previsión (Modelo Mexicano v.2.0, Modelo de Primer Orden TNO, Modelo de Primer Orden Multi-fase, Modelo EPER Francés, SWANA Orden Cero, SWANA Primer Orden Simple, SWANA Primer Orden Modificado, SWANA Primer Orden Multi-fase, LandGEM v3.02 y Scholl Canyon). En este trabajo se han contrastado estos modelos aplicándolos a los datos obtenidos en la medición de la generación de biogás entre 2009 y 2011 del relleno sanitario de HASAR'S situado en el municipio de Zapopan, en el estado de Jalisco (México) y se ha analizado el grado de coincidencia entre los modelos y el relleno. En comparación con los valores reales, los modelos TNO, SWANA de primer orden (simple y modificado) y LandGEM sobreestiman la generación de biogás. Los modelos Afvalzorg Multi-fase y Scholl Canyon, en cambio, la subestiman. Los modelos de la SWANA de primer orden y el modelo LandGEM se alejan demasiado de las mediciones reales, por lo que se debería descartar su uso en este vertedero. El Modelo Mexicano, el EPER Francés y el SWANA Orden Cero son los que más se aproximan. También se han calculado los errores relativos de los resultados proporcionados por cada modelo con respecto a la generación real medida.
\end{abstract}

Key words: sanitary landfill, biogas, mathematical model

\begin{abstract}
In order to estimate the generation of biogás in a landfill, there are some mathematical models (Modelo Mexicano v.2.0, Modelo de Primer Orden TNO, Modelo de Primer Orden Multi-fase, Modelo EPER Francés, SWANA Orden Cero, SWANAPrimer Orden Simple, SWANA Primer Orden Modificado, SWANA Primer Orden Multi-fase, LandGEM v3.02 y Scholl Canyon). In this work, these model have been compared for the sanitary landfill HASAR'S, located in Zapopan (Jalisco, México). Furthermore, the results of the models have been compared with the real data measured in the landfill from 2009 to 2011. Com-
\end{abstract}


pared to the real values, the models TNO, SWANA firts order (simple and modified) and LandGEM overestimate the generation of biogas. The models Afvalzorg multiphase and Scholl Canyon, however, underestimate. The models SWANA first order and LandGEM are very far as the real measurement, therefore its use must be rule out for this landfill. The "Modelo Mexicano de Biogás", the french EPER and SWANA order zero are the most approximate. The relative errors of the results proveded by each model with respect to measure the real generation has been calculated too.

\section{INTRODUCCIÓN}

Un parte del metano generado en los rellenos sanitarios puede capturarse y aprovecharse como una fuente de energía renovable. Si este metano es liberado a la atmósfera, contribuye al calentamiento global 21-23 veces más que el dióxido de carbono (Garg et al. 2006, Batool y Chuadhry 2008). La reacción biológica principal ocurrida en los vertederos es la digestión anaeróbica, la cual se produce en tres etapas. En la primera, bacterias fermentativas hidrolizan los complejos orgánicos en moléculas solubles. En la segunda etapa, esas moléculas son transformadas en ácidos, dióxido de carbono e hidrógeno. Estos ácidos son acético, propiónico, butírico y etanol. Finalmente, en la tercera etapa, las bacterias metanogénicas producen metano, ya sea por transformación de los ácidos en metano y dióxido de carbono o reducción del dióxido de carbono con hidrógeno.

La velocidad de descomposición de los residuos en un relleno sanitario (medida por la producción de biogás) suele llegar a su máximo dentro de los dos primeros años. A partir de este momento baja lentamente, pudiéndose mantener durante periodos de 25 años o más. Según Themellis y Ulloa (2007) basándose en la información teórico-experimental presentada en sus trabajos, puede asumirse que bajo ciertas condiciones, al menos el $50 \%$ del metano latente en los RSU (residuos sólidos urbanos) puede formarse dentro del primer año de permanencia de los residuos en el vertedero, mientras que el área del vertedero no está clausurada y el agua de lluvia puede infiltrarse y percolar en la masa de residuos. Este dato correspondería a alrededor de $50 \mathrm{Nm}^{3}$ de metano/tonelada de RU. Por otro lado, los vertederos suponen la principal fuente de metano antropogénico y se estima que de estos sitios emana del 3 al $19 \%$ de las emisiones totales (US. EPA 1995). Por tanto, la recuperación del gas del vertedero para su aprovechamiento como fuente de energía es de gran interés en vista a una solución creativa para la contaminación ambiental y para la escasez de recursos naturales (Bogner el at. 1997, Czepiel et al. 1996).
La generación de biogás dependerá del potencial de generación $\left(\mathrm{L}_{0}\right)$ y la tasa de generación de metano (k), que varían en función del índice de degradación de cada tipo de residuo orgánico (Kamalan et al. 2011, Scharff y Jacobs 2006, Aguilar-Virgen et al. 2012). Para el control y posible aprovechamiento de este biogás, se requiere primeramente estimar la generación del mismo durante la vida útil del vertedero. Es por esto que se han desarrollado diversos modelos matemáticos para predecir las emisiones de biogás en rellenos sanitarios (Aguilar-Virgen et al. 2011, López Martínez et al. 2012).

En el presente trabajo se presenta la comparación de los resultados obtenidos mediante diversos modelos de generación de biogás con las emisiones medidas en el relleno sanitario de Zapopan (Guadalajara, México)

\section{MÉTODOS}

\section{Caso de estudio}

El relleno sanitario que ha sido objeto de estudio en el presente trabajo es el vertedero de Residuos Sólidos Hasar's, que se encuentra al norte de la ciudad de Zapopan (Guadalajara, México), y ocupa una superficie de aproximadamente 32 hectáreas (Fig. 1). La disposición de residuos comenzó en el año 1998, y el vertedero se encuentra todavía en fase de operación. La fase de construcción del sistema de captura y quema del biogás de vertedero empezó a finales de 2007. Para el diseño y dimensionado de los pozos de captura y de la red de tuberías se contrató a la empresa americana SCS Engineers, que se encargó de todos los cálculos y estimaciones necesarias. En el año 2012 había depositados aproximadamente 5.5 millones de toneladas de residuos, tal y como se muestra en la Figura 2.

En este municipio no se realiza recogida selectiva, pero existen personas (ajenas a la empresa que gestiona el vertedero) que previamente a la entrada rescatan del relleno sanitario cualquier material que pueda venderse o reutilizarse: plásticos, cartón, 
latas de aluminio, férricos, etc. Esto se refleja en la composición de los residuos del vertedero, ya que se observa bajos porcentajes de metales, como muestra la Figura 3.

Para la ejecución de la primera fase del proyecto (celda 1) se contrató a la empresa mexicana MESEME S.A (México Servicios Medioambientales S.A.). Esta fase empezó en Marzo de 2008, y fue formalmente inaugurada el 6 de Febrero de 2009, cuando el sistema empezó a operar de forma continua.

El vertedero de residuos sólidos de Zapopan cuenta con un equipo completo de análisis de biogás en continuo en la línea cabecera de la tubería antes de la antorcha el cual cumple la función de hacer un análisis eficaz y continuo de los gases y un monitoreo constante de los datos resultantes del proceso. Se dispone de datos de generación de biogás en el vertedero cada 2 minutos entre Febrero de 2009 y Febrero de 2011, facilitados por la empresa responsable de la gestión del relleno sanitario.

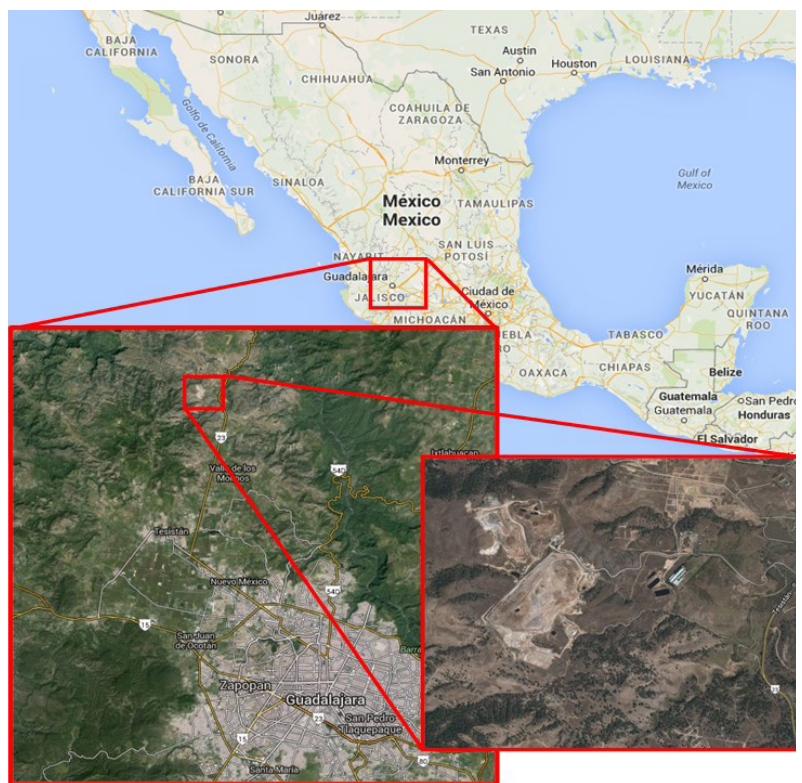

Fig. 1. Ubicación del relleno sanitario de Zapopan.

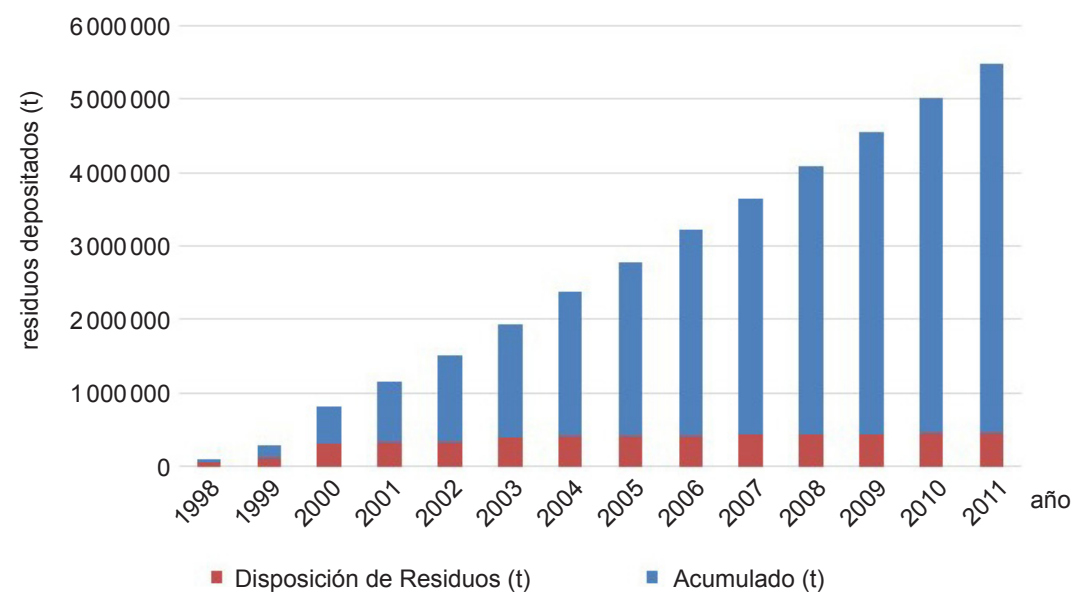

Fig. 2. Disposición de residuos en el vertedero de residuos sólidos de Zapopan

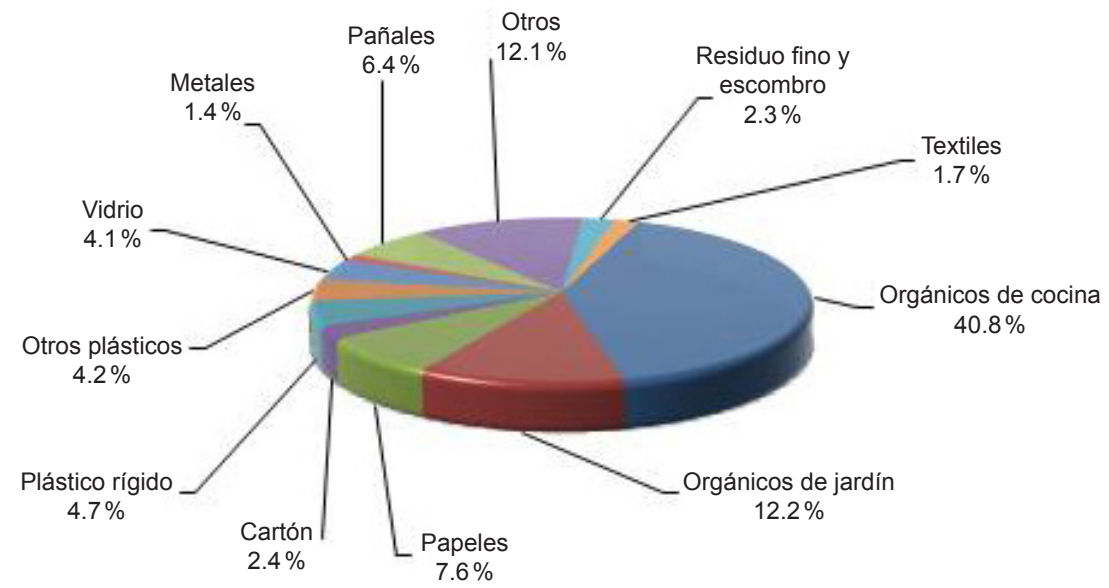

Fig. 3. Composición de los residuos en Guadalajara, México (Velázquez 2006) 
En este estudio, se han analizado 10 modelos diferentes para estimar las emisiones de biogás en el vertedero de Zapopan. Se ha tomado como base el Modelo Mexicano de Biogás, ya que incorpora información específica que le permite reflejar mejor las condiciones de clima y de los sitios de disposición final en México. El problema de este modelo es que necesita de una gran cantidad de datos específicos del sitio para poder generar la curva de gas del vertedero, lo que en ocasiones no resulta fácil de conseguir.

\section{Modelos de generación de biogás}

En este estudio, se han analizado 10 modelos diferentes para estimar las emisiones de biogás en el vertedero de Zapopan:

- Modelo Mexicano de Biogás v2.0 (SCS Engineers 2009).

- Modelo de primer orden TNO (Oonk y Boom 1995).

- Modelo de primer orden multi-fase -Afvalzorg desarrollado- (Scharf y Jacobs, 2006)

- Modelo EPER Francés (ADEME) (Scharf y Jacobs 2006).

- SWANA Zero Order Model (SWANA, 1998).

- SWANA Simple First Order Model (SWANA, 1998).

- SWANA Modified First Order Model (SWANA, 1998).

- SWANA First Order Multi-phase Model (SWANA, 1998).

- LandGEM v3.02 (US-EPA, 2005).

- Scholl Canyon.

Los resultados de los distintos modelos se compararon con los datos de generación real facilitados por la empresa que gestiona el vertedero. Con esto se pretende establecer otros modelos válidos para la simulación de curvas de gas en México. A continuación se describe individualmente tanto el modelo mexicano como el resto de modelos.

El Modelo Mexicano de Biogás estima la generación y recuperación de biogás en un vertedero mediante una ecuación de degradación de primer orden (Ecuación 1), asumiendo que el comienzo de la generación de biogás se da un año después de la colocación de los residuos (Cuadro I).

$$
Q_{\mathrm{LFG}}=\sum_{t=1}^{n} \sum_{j=0.1}^{n} 2 \mathrm{~kL}_{0}\left(\frac{\mathrm{M}_{\mathrm{i}}}{10}\right) \mathrm{e}^{-\mathrm{kt}_{\mathrm{ij}}}(\mathrm{MCF})(\mathrm{F})
$$

Donde:

$\mathrm{Q}_{\mathrm{LFG}}=$ generación anual de biogás en el año de cálculo $\left(\mathrm{m}^{3} / \mathrm{año}\right)$.

$\mathrm{i}=$ incrementos de 1 año.

$\mathrm{n}=$ (año de cálculo)-(año de inicio de disposición

de residuos).

$\mathrm{j}=$ incrementos de 0.1 año.

$\mathrm{k}=$ tasa de generación de metano $\left(\mathrm{año}^{-1}\right)$.

$\mathrm{L}_{0}=$ potencial de generación de metano $\left(\mathrm{m}^{3} /\right.$ tonelada $)$.

$\mathrm{M}_{\mathrm{i}}=$ cantidad de residuos aceptados en el año " $\mathrm{i}$ "

según valores de Figura 2 (toneladas).

$\mathrm{t}_{\mathrm{ij}}=$ edad de la sección " $\mathrm{j}$ " de residuos " $\mathrm{M}_{\mathrm{i}}$ " aceptados en el año "i".

$\mathrm{MCF}$ = factor de corrección de metano.

$\mathrm{F}=$ factor de ajuste por incendios.

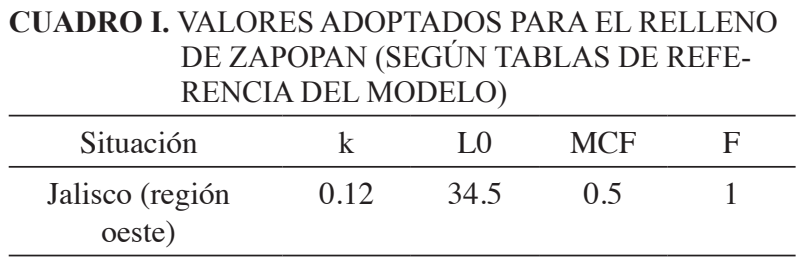

El modelo de primer orden (TNO) representa el efecto de agotamiento de carbono en los residuos a través del tiempo mediante un modelo de primer orden. Se asume que la generación de biogás a partir de una cierta cantidad de residuos decae exponencialmente con el tiempo. El modelo viene dado por la ecuación 2 :

$\alpha_{t}=\mathrm{c} \cdot 1.87 \cdot \mathrm{A} \cdot \mathrm{C}_{0} \cdot \mathrm{k}_{1} \cdot \mathrm{e}^{-\mathrm{k}_{1} \mathrm{t}}$

Donde:

$\alpha_{t}$ : generación de biogás (LFG) en un tiempo dado ( $\mathrm{m}^{3}$ LFG/año)

$\varsigma$ : factor de asimilación (0.58).

1.87: factor de conversión ( $\mathrm{m}^{3} \mathrm{LFG} / \mathrm{kg} \mathrm{C}$ degradados) A: cantidad de residuos en el sitio de disposición final (toneladas).

$\mathrm{C}_{0}$ : cantidad de carbono orgánico en los residuos ( $\mathrm{kg} \mathrm{C} /$ tonelada de residuo)

$\mathrm{k}_{1}$ : constante de degradación $\left(\mathrm{año} \mathrm{o}^{-1}\right)$.

t: tiempo transcurrido desde la deposición de los residuos (años).

El vertedero de Zapopan recibe los residuos domésticos provenientes de los municipios de Zapopan, Tesistán y Guadalajara, por lo que la cantidad de carbono orgánico en los residuos $\left(\mathrm{C}_{0}\right)$ se estima en 130 $\mathrm{kg}$ C/tonelada RS. Se asume que el biogás contiene 
CUADRO II. VALORES ADOPTADOS PARA EL RELLENO DE ZAPOPAN (SEGÚN TABLAS DE REFERENCIA DEL MODELO)

\begin{tabular}{|c|c|c|c|c|c|c|c|c|c|c|}
\hline$c$ & $\mathrm{k}_{1}$ & $\mathrm{k}_{2}$ & $\mathrm{k}_{3}$ & $\mathrm{i}_{1} / \mathrm{p}_{1}$ & $\mathrm{i}_{2} / \mathrm{p}_{2}$ & $\mathrm{i}_{3} / \mathrm{p}_{3}$ & $\mathrm{C}_{0,1}$ & $\mathrm{C}_{0,2}$ & $\mathrm{C}_{0,3}$ & 5 \\
\hline 0.75 & 0.220 & 0.071 & 0.020 & 0.482 & 0.239 & 0.000 & 70 & 90 & 48 & 0.9 \\
\hline
\end{tabular}

un $50 \%$ en volumen de metano, y que la materia orgánica (MO) está compuesta principalmente de celulosa.

En el modelo Afvalzorg multi-fase cada tipo de residuos contiene distintas fracciones de materia orgánica, que se degradan a diferentes tasas. En este modelo se distinguen ocho categorías de residuos y tres fracciones. Para cada fracción de residuo se calcula su producción de biogás por separado (Cuadro II). Se trata de un modelo de primer orden, que se describe matemáticamente con la ecuación 3:

$\alpha_{t}=\mathrm{c} \sum_{\mathrm{i}=1}^{3} \mathrm{c} \cdot \mathrm{A} \cdot \mathrm{C}_{0, \mathrm{i}} \cdot \mathrm{k}_{1, \mathrm{i}} \cdot \mathrm{e}^{-\mathrm{k}_{1, \mathrm{i}} \mathrm{t}}$

Donde:

A: cantidad de residuos en el sitio de disposición final según valores de la Figura 2 (toneladas).

$\alpha_{t}$ : generación de biogás (LFG) en un tiempo dado ( $\left.\mathrm{m}^{3} \mathrm{LFG} / \mathrm{año}\right)$

i: fracción de residuo con tasa de degradación $\mathrm{k}_{1, \mathrm{i}}$ ( $\mathrm{kg}_{\mathrm{i}} / \mathrm{kg}$ residuos)

c: factor de conversión $\left(\mathrm{m}^{3} \mathrm{LFG} / \mathrm{kg}\right.$ materia orgánica degradada)

$\mathrm{k}_{1, \mathrm{i}}$ : constante de degradación $\left(\mathrm{añon}^{-1}\right)$.

El modelo EPER francés da dos enfoques para estimar las emisiones de metano de los vertederos. El operador puede seleccionar la estimación de las emisiones de metano de las células del vertedero conectadas o no a un sistema de recuperación de biogás utilizando un modelo multifase (versión 15/12/2002 ADEME) y la eficiencia del sistema (Ecuación 4).

$\mathrm{FE}_{\mathrm{CH}_{4}}=\sum_{\mathrm{x}} \mathrm{FE}_{0}\left(\sum_{1,2,3} \mathrm{~A}_{\mathrm{i}} \cdot \mathrm{p}_{\mathrm{i}} \cdot \mathrm{k}_{\mathrm{i}} \cdot \mathrm{e}^{-\mathrm{k}_{\mathrm{i}} \mathrm{t}}\right)$

Donde:

$\mathrm{FE}_{\mathrm{CH} 4}$ : generación de metano anual $\left(\mathrm{m}^{3} \mathrm{CH}_{4} / \mathrm{año}\right)$.

$\mathrm{FE}_{0}$ : potencial de generación de metano $\left(\mathrm{m}^{3} \mathrm{CH}_{4} /\right.$ tonelada RS).

$\mathrm{p}_{\mathrm{i}}$ : fracción de residuo con tasa de degradación $\mathrm{k}_{\mathrm{i}}$ ( $\mathrm{kg}_{\mathrm{i}} / \mathrm{kg}$ residuos).

ki: constante de degradación de la fracción i $\left(a n ̃ o^{-1}\right)$.

Ai: factor de normalización (-).

t: edad de los residuos (años).
No obstante, para que las unidades coincidan en la Ecuación 4 se hace necesario multiplicar al factor de la izquierda por la tasa de disposición anual de residuos $\left(\mathrm{W}_{\mathrm{i}}\right)$, según los valores de la Figura 2 (toneladas/año).

El modelo SWANA zero order fue desarrollado por la SWANA (Solid Waste Association of North America) (SWANA 1998) para calcular la generación de metano en vertederos. Este tipo de modelos suponen que la edad y el tipo de residuos no tienen ningún efecto sobre la producción de biogás (Ecuación 5).

$\mathrm{Q}=\frac{\mathrm{M} \cdot \mathrm{L}_{0}}{\left(\mathrm{t}_{0}-\mathrm{t}_{1}\right)}$ para $\mathrm{t}_{0}<\mathrm{t}<\mathrm{t}_{1}$

Donde:

$\mathrm{Q}=$ generación de metano $\left(\mathrm{m}^{3} / \mathrm{año}\right)$.

$M=$ residuos depositados en el vertedero según los valores de la Figura 2 (toneladas)

$\mathrm{L}_{0}=$ potencial de generación de metano

$\mathrm{t}=$ tiempo (años)

$\mathrm{t}_{0}=$ tiempo de desfase (años)

$\mathrm{t}_{1}=$ tiempo de cese de generación (años).

Para el presente trabajo, el valor de potencial de generación de metano se ha fijado a partir de los datos del Modelo mexicano de Biogás $\left(\mathrm{L}_{0}=34.51 \mathrm{~m}^{3} \mathrm{CH}_{4} /\right.$ tonelada RS), mientras que el valor del tiempo de cese se ha fijado en 25 años.

En el modelo SWANA Simple First Order Model se incorporan los efectos que la variable "edad de los residuos" provoca en la generación de biogás. Los modelos de primer orden asumen que la tasa de generación decae exponencialmente con el tiempo (Ecuación 6).

$\mathrm{G}=\mathrm{W} \cdot \mathrm{L}_{0} \cdot \mathrm{k} \cdot \mathrm{e}^{-\mathrm{k}\left(\mathrm{t}-\mathrm{t}_{1}\right)}$

Donde:

$\mathrm{G}=$ generación de metano ( $\left.\mathrm{m}^{3} / \mathrm{año}\right)$.

$\mathrm{W}=$ residuos en el vertedero según los valores de la Figura 2 (toneladas).

$\mathrm{t}_{1}=$ tiempo de desfase (entre la disposición de los RS y el inicio de la generación).

$\mathrm{k}=$ constante de degradación de primer orden $\left(\operatorname{años}^{-1}\right)$. 
Los valores de la constante de degradación y el potencial de generación de metano se han obtenido como media ponderada de los valores utilizados en el Modelo Mexicano de Biogás, siendo $\mathrm{k}=0.12$ y $\mathrm{L}_{0}=34.5$. El valor del tiempo de cese se ha fijado en 25 años.

El modelo SWANA Modified First Order Model asume que la generación/recuperación de metano puede ser inicialmente baja, es decir, que hay un retraso en el inicio de la generación. Luego la recuperación irá en aumento hasta llegar a un máximo antes de comenzar a disminuir, en lo que es esencialmente una forma exponencial (Ecuación 7).

$\mathrm{G}=\mathrm{W} \cdot \mathrm{L}_{0} \cdot \frac{\mathrm{k}+\mathrm{s}}{\mathrm{s}}\left(1-\mathrm{e}^{-\mathrm{s}\left(\mathrm{t}-\mathrm{t}_{1}\right)}\right) \cdot\left(\mathrm{k} \cdot \mathrm{e}^{-\mathrm{k}\left(\mathrm{t}-\mathrm{t}_{1}\right)}\right)$

Donde:

$\mathrm{W}=$ residuos en el vertedero según los valores de la

Figura 2 (toneladas).

$\mathrm{t}=$ tiempo desde el depósito de los RS (años).

$\mathrm{s}=$ constante de fase de primer orden.

Se han utilizado los mismos valores de potencial de generación de metano y de constante de degradación que en el caso del modelo de primer orden simple de la SWANA.

El modelo SWANA First Order Multi-fase Model es una mejora del modelo modificado de primer orden. Sus supuestos son los mismos, excepto que las diferentes fracciones de residuos se supone que se descomponen a diferentes tasas. Diversas variantes de este modelo se aplican comercialmente (Ecuación 8 ). Este modelo dio los mejores resultados (por poco margen) en el trabajo de modelado de Oonk et al. (1994).

$\mathrm{G}=\mathrm{W} \cdot \mathrm{L}_{0} \cdot\left[\mathrm{F}_{(\mathrm{r})}\left(\mathrm{k}_{(\mathrm{r})} \cdot \mathrm{e}^{-\mathrm{k}_{(\mathrm{r})}\left(\mathrm{t}-\mathrm{t}_{1}\right)}\right)+\mathrm{F}_{(\mathrm{s})}\left(\mathrm{k}_{(\mathrm{s})} \cdot \mathrm{e}^{-\mathrm{k}\left(\mathrm{t}-\mathrm{t}_{1}\right)}\right)\right]$

Donde:

$\mathrm{W}=$ residuos en el vertedero según los valores de la

Figura 2 (toneladas).

$\mathrm{k}_{(\mathrm{r})}=$ constante de degradación de la fracción de RS con degradación rápida $\left(\right.$ años $\left.^{-1}\right)$

$\mathrm{k}_{(\mathrm{s})}=$ constante de degradación de la fracción de RS con degradación lenta (años $\left.{ }^{-1}\right)$

$\mathrm{F}_{(\mathrm{r})}=$ fracción de $\mathrm{RS}$ con degradación rápida (\%).

$\mathrm{F}_{(\mathrm{s})}=$ fracción de RS con degradación lenta $(\%)$.

El modelo LandGEM, desarrollado por la EPA de EEUU, también utiliza una ecuación de primer orden para estimar la generación de biogás con el tiempo.
$\mathrm{Q}_{\mathrm{CH}_{4}}=\sum_{\mathrm{t}=1}^{\mathrm{n}} \sum_{\mathrm{j}=0.1}^{1} \mathrm{~kL}_{0}\left(\frac{\mathrm{M}_{\mathrm{i}}}{10}\right) \mathrm{e}^{-\mathrm{kt}_{\mathrm{ij}}}$

Donde,

$\mathrm{Q}_{\mathrm{CH} 4}=$ generación anual de metano en el año de cálculo $\left(\mathrm{m}^{3} / \mathrm{año}\right)$

$\mathrm{i}=$ incrementos de 1 año

$\mathrm{n}=$ (año de cálculo)-(año de inicio de disposición

de residuos)

$\mathrm{j}=$ incrementos de 0,1 año.

$\mathrm{k}=$ tasa de generación de metano $\left(\right.$ año $\left.\mathrm{O}^{-1}\right)$

$\mathrm{L}_{0}=$ potencial de generación de metano $\left(\mathrm{m}^{3} / \mathrm{Mg}\right)$

$\mathrm{M}_{\mathrm{i}}=$ cantidad de residuos aceptados en el año " $\mathrm{i}$ " según los valores de la Figura 2 (toneladas)

$\mathrm{t}_{\mathrm{ij}}=$ edad de la sección " $\mathrm{j}$ " de residuos "Mi" aceptados en el año "i"

Los valores de la constante de degradación y el potencial de generación de metano se han elegido según los valores por defecto que proporciona el modelo, siendo $\mathrm{k}=0.05$ (año-1) y $\mathrm{L}_{0}=100\left(\mathrm{~m}^{3} / \mathrm{Mg}\right)$.

El modelo Scholl Canyon también se trata de un modelo de degradación de primer orden. Asume que la generación de biogás llega al máximo después de la fase inicial de estabilización, mientras se equilibran las condiciones anaerobias y las poblaciones de microorganismos dentro del relleno sanitario. Después decrece la tasa de producción de biogás debido a la disminución de la fracción orgánica de los residuos en el relleno sanitario. Está descrito por la ecuación 10:

$\mathrm{Q}=\mathrm{k} \cdot \mathrm{L}_{0} \cdot \mathrm{R} \cdot \mathrm{e}^{-\mathrm{k}(\mathrm{t}-\mathrm{x})}$

Donde:

$\mathrm{Q}=$ generación de biogás ( $\left.\mathrm{m}^{3} / \mathrm{año}\right)$

$\mathrm{R}=$ residuos en el vertedero según los valores de la Figura 2 (toneladas)

$(\mathrm{t}-\mathrm{x})=$ antigüedad de cada periodo de disposición: $0,1,2,3, \ldots$ (años)

Los valores de la constante de degradación y el potencial de generación de metano se han elegido según los valores del Modelo Mexicano del Biogás, siendo $\mathrm{k}=0.12\left(\mathrm{año}^{-1}\right)$ y $\mathrm{L}_{0}=34.5\left(\mathrm{~m}^{3} / \mathrm{Mg}\right)$.

\section{RESULTADOS Y DISCUSIÓN}

En la Figura 4 y Figura 5 se presentan los resultados de las estimaciones con los diferentes modelos y las mediciones reales. Según la Figura 5 los modelos que más se aproximan a la generación real de biogás son el modelo EPER France, El Modelo Mexicano del Biogás y del de la SWANA zero order. 


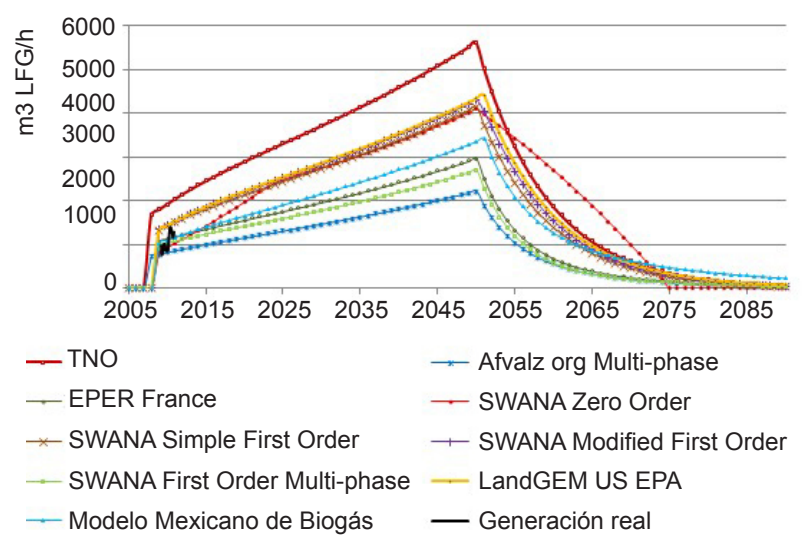

Fig. 4. Comparación del resultado obtenido en los modelos

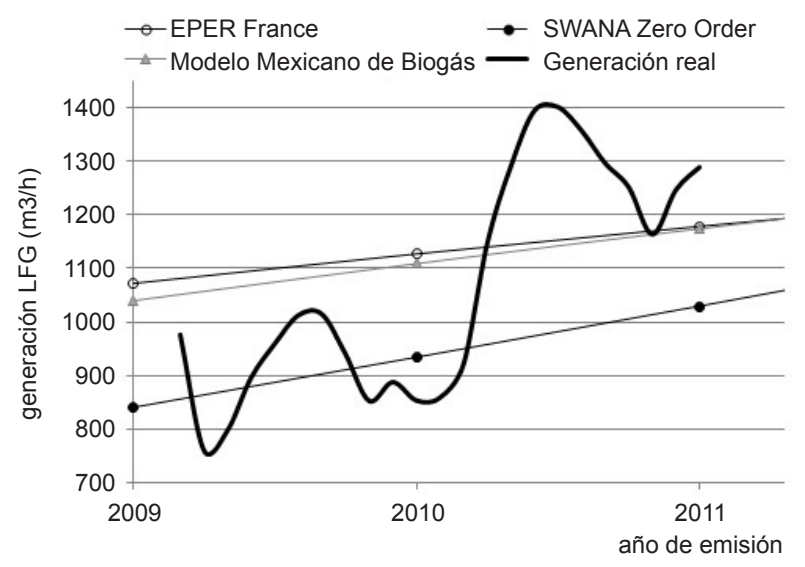

Fig. 5. Detalle de los modelos más aproximados a la generación real

Según el SWANA Zero Order Model la composición de los residuos y la edad de los mismos no tiene efecto en la generación de biogás. El modelo de orden cero supone que durante el periodo en el que los residuos generan biogás (15-25 años) lo hacen de forma constante, por lo que la cantidad de biogás generado dependerá únicamente de la cantidad de residuos depositados. A pesar de esta gran simplificación, los resultados obtenidos se aproximan mucho a los valores medidos.

En comparación con los valores reales, los modelos TNO, SWANA de primer orden (simple y modificado) y LandGEM sobreestiman la generación de biogás en el periodo 2009-2011. Los modelos Afvalzorg Multi-fase y Scholl Canyon, en cambio, la subestiman. Los modelos de la SWANA de primer orden y el modelo LandGEM se alejan demasiado de las mediciones reales, por lo que se debe descartar su uso en este relleno sanitario, o en todo caso se debería aplicar un factor de corrección.
Con el tiempo estos tres modelos proporcionan datos de generación muy dispares, según los siguientes resultados:

EPER Francés $\approx 3000 \mathrm{~m}^{3} / \mathrm{h}$.

Modelo Mexicano $\approx 3500 \mathrm{~m}^{3} / \mathrm{h}$.

SWANA Zero Order Model $\approx 4000 \mathrm{~m}^{3} / \mathrm{h}$.

La tendencia de los datos analizados parece indicar que el modelo de orden cero y el mexicano serán los que mejor reflejarán en un futuro la generación de biogás en el vertedero de Zapopan.

Si se calculan los errores relativos (Ecuación 11) para cada uno de los modelos anteriores con respecto a la generación real del relleno estudiado se puede observar una disparidad en los resultados (Cuadro III).

$\mathrm{Err}=\frac{|\mathrm{G}-\mathrm{Gr}|}{\mathrm{Gr}} \cdot 100$

Donde:

Err $=$ Error relativo $(\%)$

$\mathrm{G}=$ Generación de biogás según modelo

$\mathrm{Gr}=$ Generación real medida en el relleno de Hasar's

CUADRO III. ERROR RELATIVO DE LOS MODELOS RESPECTO A LA GENERACIÓN REAL

\begin{tabular}{lc}
\hline Modelo & Error relativo medio (\%) \\
\hline TNO & 53 \\
Afvalzorg & 15 \\
EPER France & 40 \\
SWANA Zero Order & 41 \\
SWANA First Order & 32 \\
SWANA First Order Modified & 30 \\
SWANA First Order Multi-phase & 54 \\
LandGEM & 108 \\
Modelo Mexicano & 16 \\
Scholl Canyon & 42 \\
\hline
\end{tabular}

En la Figura 6 se representa la evolución de los errores que presentan cada uno de los modelos con respecto a la generación real, tanto la curva de los errores mesuales como la línea de tendencia de cada error (en línea recta sólida).

Por otra parte, si se observan los datos del Cuadro IV puede apreciarse un cambio muy grande a partir del mes de Marzo de 2011. Los datos hasta 

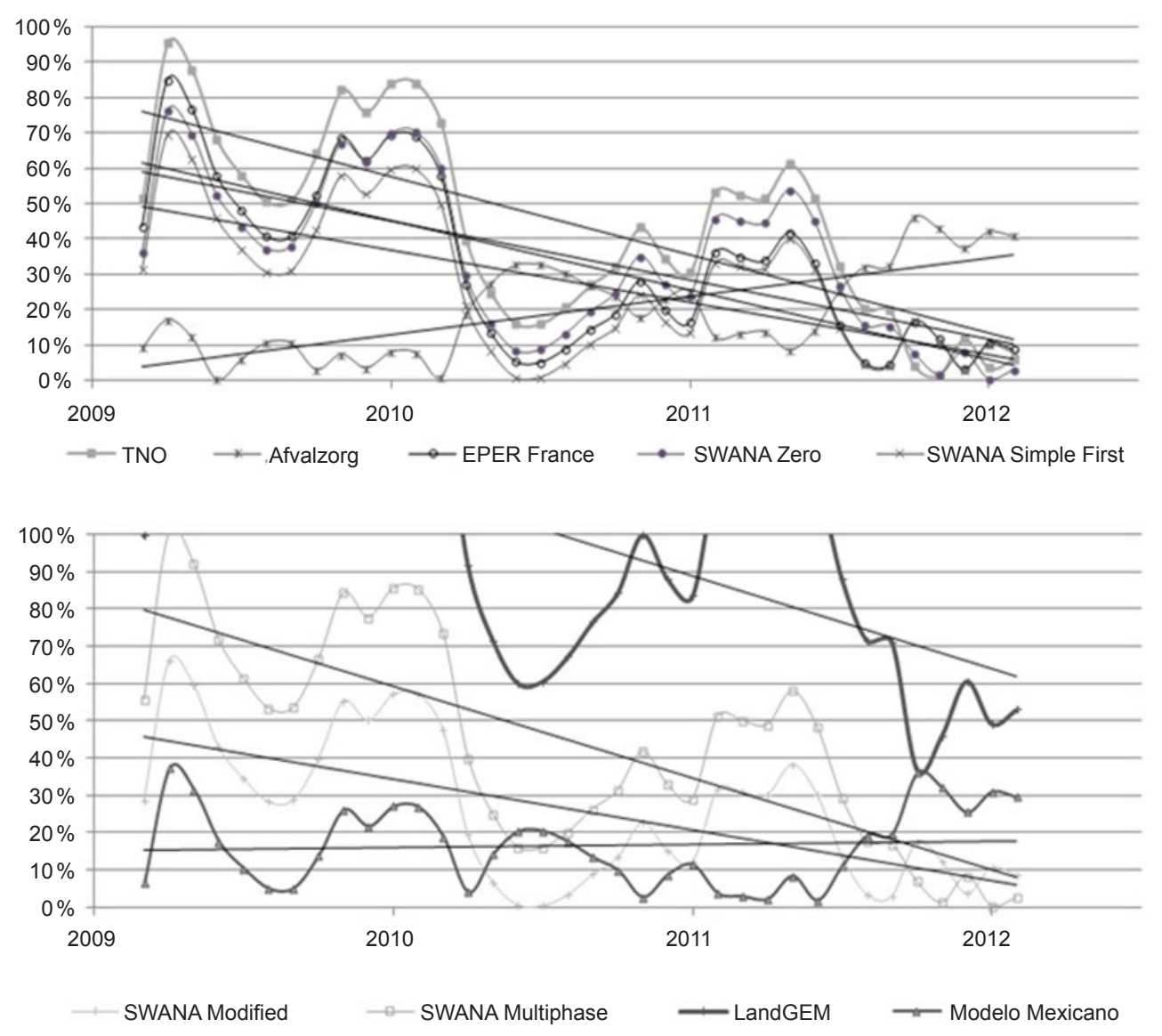

Fig. 6. Evolución de los errores de la línea obtenida de los modelos con respecto a la generación real

ese mes están dentro de una tendencia más o menos uniforme, pero a partir de entonces es cuando disminuye la concentración de metano y sube la concentración de $\mathrm{O}_{2}$ (se recomienda que no suba nunca del $3.5 \%$ porque puede producir mezclas explosivas (Pascal et al. 1994, Mandeno et al. 2005). Además baja mucho el tiempo operativo del sistema, ya que la mayor parte del tiempo está con caudales muy bajos. Cuando el caudal se situa por debajo del 25 $\%$ se detecta un porcentaje muy bajo de $\mathrm{CH}_{4}$ en el biogás, por lo que la llama de la antorcha se apaga y se reinicia el sistema de toma de datos. Por ello, en la cuarta columna del Cuadro IV se descartan estos valores de caudal.

A partir de la fecha indicada (marzo de 2011) Los datos dejan de seguir una tendencia uniforme debido a que:

- Aproximadamente el $60 \%$ del tiempo el caudal (Q) está por debajo de unos $13 \mathrm{~m}^{3} / \mathrm{h}$, lo cual no se considera significativo.

- Por lo tanto, si se calcula el valor de caudal teniendo en cuenta todos los datos se obtiene un valor medio de caudal muy bajo (aproximadamente $600 \mathrm{~m}^{3} / \mathrm{h}$ ).

- Si en cambio se excluyen los datos menores de $13 \mathrm{~m}^{3} / \mathrm{h}$ para hacer la media, el valor que se obtiene es de unos $1800 \mathrm{~m}^{3} / \mathrm{h}$, que es demasiado alto, pero tiene su explicación. Estos datos tienen una media de contenido de metano menor del $20 \%$, y un contenido de oxigeno de más del $8 \%$, es decir, se está succionando demasiado, y eso prácticamente no se puede considerar ni biogás con un contenido de metano tan bajo, ya que incluso la llama de la antorcha se apaga y se tiene que reiniciar el sistema de toma de datos.

\section{CONCLUSIONES}

Analizando la Figura 5 se puede concluir que en función de la línea de tendencia, los modelos que más se ajustan al caso real son el de Afvalzorg y el modelo mexicano del biogás, ya que tiene el porcentaje de error promedio más bajo (Cuadro III). Sin embargo en el modelo de Afvalzorg el error va 
CUADRO IV. CARACTERISTICAS DEL BIOGÁS Y DEL FLUJO

\begin{tabular}{|c|c|c|c|c|c|}
\hline Periodo & Tiempo operativo & $\begin{array}{l}\text { Q medio (con todos } \\
\text { los datos) }\end{array}$ & $\begin{array}{l}\text { Q medio (descartando } \\
\text { valores }<25 \mathrm{~m}^{3} / \mathrm{h} \text { ) }\end{array}$ & $\% \mathrm{CH}_{4}$ & $\% \mathrm{O}_{2}$ \\
\hline Abril'10 & $77 \%$ & 886.1 & 1145.2 & 33.6 & 2.4 \\
\hline Mayo'10 & $81 \%$ & 1031.1 & 1289.4 & 31.6 & 2.7 \\
\hline Junio'10 & $73 \%$ & 1006.9 & 1393.4 & 36.1 & 1.7 \\
\hline Julio'10 & $66 \%$ & 917.8 & 1400.4 & 39.6 & 1.6 \\
\hline Agosto' 10 & $78 \%$ & 1052.3 & 1356.4 & 36.8 & 2.6 \\
\hline Septiembre'10 & $81 \%$ & 1048.6 & 1295.8 & 38.1 & 2.4 \\
\hline Octubre'10 & $63 \%$ & 785.2 & 1251.1 & 38.7 & 1.6 \\
\hline Noviembre'10 & $61 \%$ & 708.5 & 1163.2 & 29.3 & 2.5 \\
\hline Diciembre'10 & $60 \%$ & 735.1 & 1246.2 & 29.9 & 2.5 \\
\hline Enero'11 & $59 \%$ & 751.65 & 1288.2 & 34.6 & 2.1 \\
\hline Febrero'11 & $60 \%$ & 655.8 & 1104.3 & 33.6 & 2.5 \\
\hline Marzo’11 & - & - & - & - & - \\
\hline Abril'11 & $68.8 \%$ & 736.7 & 1129.6 & 28 & 4.5 \\
\hline Мayo’11 & $68.2 \%$ & 716.4 & 1069 & 27.2 & 4.3 \\
\hline Junio'11 & $60.5 \%$ & 627.6 & 1142.5 & 22.9 & 5 \\
\hline Julio’11 & $53.4 \%$ & 771.6 & 1454 & 26.6 & 5.8 \\
\hline Agosto'11 & $38.1 \%$ & 469.3 & 1316.8 & 20.5 & 7.3 \\
\hline Septiembre'11 & $58.5 \%$ & 529.1 & 1467.9 & 16.8 & 7.4 \\
\hline Octubre'11 & $35.3 \%$ & 360.8 & 1847.4 & 12.4 & 13 \\
\hline Noviembre'11 & $38.9 \%$ & 654.4 & 1747.7 & 8.53 & 14 \\
\hline Diciembre'11 & $31.3 \%$ & 416.9 & 1599.4 & 19.8 & 7.7 \\
\hline Enero'12 & $20 \%$ & 367.6 & 1734.3 & 16.2 & 9 \\
\hline Febrero'12 & $32.6 \%$ & 476.4 & 1704.1 & 18 & 8 \\
\hline Marzo'12 & $29 \%$ & 526.7 & 1784 & 17.1 & 8 \\
\hline
\end{tabular}

aumentando a medida que transcurre el tiempo, por lo que, si siguiere esta tendencia, el resultado final se iría alejando cada vez más del real. Por el contrario, el resto de modelos muestran una línea de tendencia descendente, por lo que previsiblemente los resultados finales se acercarían más a la generación real.

\section{AGRADECIMIENTOS}

Los autores agradecen la financiación del proyecto con código P11B2011-34 dentro del marco de Proyectos de Investigación de la Acción 1.1. de la Convocatoria de Proyectos de Investigación Científica y Desarrollo Tecnológico del Plan de
Promoción de la Investigación de la Universidad Jaume I - Bancaixa, con el título "Posibilidades de biometanización a partir de distintos tipos de residuos biodegradables".

\section{REFERENCIAS}

Aguilar-Virgen Q., Taboada-González P.A. y OjedaBenitez S. (2011). Modelo mexicano para la estimación de la generación de biogás. Ingeniería 15(1) 37-45.

Aguilar-Virgen Q., Ojeda-Benitez S., Taboada-González P.A. y Quintero-Núñez M. (2011). Estimación de las constantes k y L0 de la tasa de generación de biogás en sitios de disposición final en Baja California, México Rev. Int. Contam. Ambie. 28, 43-49. 
Batool S.A. y Chuadhry M.N. (2008). The impact of municipal solid waste treatment methods on greenhouse gas emissions in Lahore, Pakistan. Waste Manage. 29(1), 63-69.

Bogner J.E., Spokas K. y Burton E.A. (1997). Kinetics of methane oxidation in a landfill cover soil: temporal variations, a whole-landfill oxidation, and modeling of net $\mathrm{CH}_{4}$ emissions. Environ. Sci. Technol. 31, 25042514. DOI: $10.1021 /$ es960909a

Czepiel P.M., Mosher B., Crill P.M. y Harris R.C. (1996). Quantifying the effect of oxidation on landfill methane emissions. J. Geophys. Res. 101, 16721-16729

DOI: 10.1029/96JD00222

Garg A., Achari G. y Joshi R.C. (2006). A model to estimate the methane generation rate constant in sanitary landfills using fuzzy synthetic evaluation. Waste Manage. Res. 24(4), 363-375.

DOI: $10.1177 / 0734242 X 06065189$

Kamalan H., Sabour M., y Shariatmadari N. (2011). A review on available landfill gas models. J. Environ. Sci. and Technol. 4(2), 79-92 DOI: 10.3923/jest.2011.79.92

López A., Gonzalorena R.J., Cuartas M. y Lobo A. (2012). Modelación de una celda vertedero experimental con MODUELO 4.0. Rev. Int. Contam. Ambie. 28, 89-96.

Mandeno G., Craggs R., Tanner C., Sukias J. y Websterbrown J. (2005). Potential biogas scrubbing using a high rate pond. Water Sci \& Technol. 51, 253-256.

Oonk J., Weenk A., Coops O. y Luning L. (1994). Validation of landfill gas formation models. Studies in
Environmental Science 65, 597-602. http://dx.doi. org/10.1016/S0166-1116(06)80251-7

Oonk H. y Boom T. (1995). Landfill gas formation, recovery and emission. TNO-rapport 95-203, TNO, Apeldoorn. 148 pp.

Pascal A.B., Giraud M., Legendre J.F. y Catoire L. (1994). Detonability limits of methane-oxygen mixtures at elevated initial pressures. Propellants, Explosives, Pyrotechnics 19, 311-314.

DOI: $10.1002 /$ prep.19940190609

Scharff H. y Jacobs J. (2006). Applying guidance for methane emission estimation for landfills. Waste Manage. 26, 417-429. http://dx.doi.org/10.1016/j. wasman.2005.11.015

SCS Engineers. (2009). Manual de Usuario Modelo Mexicano de Biogás Versión 2.0 [en línea]. http://www.epa. gov/lmop/documents/pdfs/manual_del_usuario_modelo_mexicano_de_biogas_v2_2009.pdf 22/02/2014

SWANA (1998). Comparison of models for predicting landfill methane recovery. Publication No. GR-LG 0075. The Solid Waste Association of North America, Dallas, TX. [en línea]. http://www.osti.gov/scitech/ biblio/314088 02/02/2014

Themelis N. J. y Ulloa P. A. (2007). Methane generation in landfills. Renew. Energ. 32 (7), 1243-1257. http:// dx.doi.org/10.1016/j.renene.2006.04.020

US-EPA (2005). Landfill Gas Emissions Model (LandGEM) Version 3.02 User's Guide, EPA-600/R-05/047. [en línea]. http://www.epa.gov/ttn/catc/dir1/landgem-v302-guide.pdf USA. 20/01/2015. 